\title{
Annual Screening
}

National Cancer Institute

\section{Source}

National Cancer Institute. Annual Screening. NCI Thesaurus. Code C62682.

A once yearly checking for disease in the absence of symptoms. 